\title{
Amantadine hydrochloride treatment in heredodegenerative ataxias: a double blind study
}

\author{
M I Botez, Thérèse Botez-Marquard, Robert Elie, Olga-Lucia Pedraza, Kristine Goyette, \\ Robert Lalonde
}

\begin{abstract}
Objective-A group of 27 patients with Friedreich's ataxia and another group of 30 patients with olivopontocerebellar atrophies were each randomly divided into two subgroups, one receiving placebo and the other amantadine hydrochloride (AH; $200 \mathrm{mg}$ daily) for three to four months. Methods-The effect of double blind treatment was evaluated by simple visual and auditory reaction time (RT) and movement time (MT) for both right and left hands.

Results-The subgroup with olivopontocerebellar atrophies receiving AH showed significant improvement on seven out of eight variables studied by analysis of covariance. In patients with Friedreich's ataxia, improvement was definitely less. Treatment remained contraindicated for those with cardiomyopathies or drug intolerance.

Conclusion-The rationale of AH use in heredodegenerative ataxias can be explained by its replacement effect (dopamine release) and by direct involvement of N-methyl-D-aspartate (NMDA) in glutamate mediated neurotoxicity in cerebellar granular cells; memantine, an AH analogue, is a potent blocker of NMDA receptors.
\end{abstract}

(F Neurol Neurosurg Psychiatry 1996;61:259-264)

Keywords: amantadine hydrochloride; Friedreich's ataxia; olivopontocerebellar atrophy; reaction time; movement time

Neurology Service M I Botez Th Botez-Marquard O-L Pedraza

$\mathrm{R}$ Lalonde

Department of

Pharmacy

K Goyette

Hôtel-Dieu de Montréal and Louis-H Lafontaine Hospital affiliated with the Université de Montréal R Elie

Correspondence to: Dr M I Botez,

Neurobehavioral Research Unit, Neurology Service, Hôtel-Dieu de Montréal, 3840 St Urbain Street, Montréal, Québec, Canada H2W 1 T8.

Received 20 July 1995 and in final revised form 1 May 1996

Accepted 29 May 1996
(MT) assessments exclusively as strictly objective measures.

\section{Materials and methods}

METHODS

Routine neurological examinations as well as a reinforcement technique for detecting latent parkinsonian rigidity 5 and akinesia were performed independently by two neurologists (MIB and OLP). The degree of ataxia of the upper and lower limbs was evaluated clinically as mild, moderate, or severe according to previously established criteria. ${ }^{6}$ Ataxia in patients with olivopontocerebellar atrophies was assessed for both upper and lower limbs. In patients with Friedreich's ataxia, it was done only for the upper limbs because the patients were already paraplegic. Hand grip strength was evaluated with a Smedley dynamometer ${ }^{7}$; those who were unable to show a minimum grip strength of $5 \mathrm{~kg}$ with each hand were considered to have severe motor disturbances and were consequently ruled out from the study. The rationale for this decision was that patients with a grip strength of $5 \mathrm{~kg}$ are capable of pressing the RT key with a minimum force of $5 \mathrm{~g}$. Every two to three weeks during the trial, the patients were telephoned to obtain information about medication compliance and possible side effects. During a visit at the end of the trial, the patients had to respond to two written questionnaires: one on possible side effects and the other about their subjective assessment of treatment. The questionnaire on side effects included insomnia, nightmares, hallucinations, depression, difficulties in concentrating, blurred vision, dizziness, loss of appetite, weight loss, and constipation. The questionnaire on the subjective assessment of treatment included general condition and mood, coordination of the upper limbs, self evaluation of dysarthria, and some specific abilities in everyday life such as the time required to cut or chop vegetables or meat for meals. In addition, patients who could walk (usually patients with olivopontocerebellar atrophy) were required to evaluate their gait and their ability to turn around, and the possibility and time required for transfer from a chair to the bath. We also evaluated the number of falls during treatment, taking as baseline the number of falls during a three month period preceding inclusion in the study. Patients were considered improved when the answers were positive for at least three variables from the above mentioned questionaire and evaluation of the number of falls. 
As in our previous open study, ${ }^{3}$ the reasons for using RT and MT as objective pretreatment and post-treatment assessments in this trial were twofold: (1) no practice effects occur in RT and MT tests ${ }^{8-10}$; (2) earlier work in our laboratory has shown lengthened RT and MT in patients with cerebellar disease. ${ }^{11-13}$

Recognised as one of the best behavioural measures of CNS integrity, ${ }^{14-16}$ RT primarily reflects the speed and efficiency of information processing. ${ }^{15}$ Although RT involves both central (premotor) and peripheral (muscle contraction) components, it has been shown by EMG that the central component comprises most of the stimulus-response latency and is primarily related to cognitive slowing. ${ }^{17}$

Whereas RT is considered to be a test of cognition, MT strictly evaluates effective motor function (motor abilities). ${ }^{18}$ These tests are thus independent measures. ${ }^{12} 1618$

Simple, forewarned visual and auditory RT and MT were studied separately with a Lafayette apparatus (model No 63107) according to the technique of Hamsher and Benton. ${ }^{18}$ This technique allows each patient five practice trials followed by 18 trials of warned, simple visual and auditory RT and MT. After the warning signal (a white light), there is a latency period varying from two to four seconds. This period was chosen randomly, and all patients were tested in the same random order. Before the warning signal was given, the patients had to press the first of two keys with their index finger (a minimum force of $5 \mathrm{~g}$ was required). At the end of the latency period, a second stimulus appeared (a red light $1 \mathrm{~cm}$ in diameter placed centrally $1 \mathrm{~m}$ from the patients for the visual test or a white sound of $80 \mathrm{~dB}$ for the auditory test). The second stimulus was a signal for the patients to release their index finger immediately (RT), and to move it as quickly as possible to the second key (MT). The distance between the keys was $15 \mathrm{~cm}$. An electronic chronometer registered $\mathrm{RT}$ and total time (RT + MT) in ms. To avoid methodological problems related to handedness, patients were asked to start either with the right or left hand as determined by a table of randomisation. On the final examination, they used the same sequence with their hands. The means (SEM) of RT and MT were calculated for 18 trials per patient. The following variables were determined for the right and left hands: visual RT (VRT-R, VRTL), visual MT (VMT-R, VMT-L), auditory RT (ART-R, ART-L), and auditory MT (AMT-R, AMT-L). All measurements were conducted before and after completion of the double blind clinical trial.

Brain CT was carried out on all patients with an Elscint apparatus. Those showing central (ventricular dilatation) and cortical (cortical sulci dilatation) atrophies according to previously defined radiological criteria ${ }^{19}$ were excluded so that only patients with clearly identified cerebellar damage were included in this study. Others excluded were alcoholic and epileptic patients and those with corrected visual acuity of less than $5 / 10$ in one eye. Patients with cardiomyopathies and cardiac arrhythmias were also ruled out because $\mathrm{AH}$ is contraindicated in cardiac diseases.

\section{PATIENTS}

Patients were enrolled from the Ataxia Clinic of Hôtel-Dieu de Montréal in order of presentation at the outpatient clinic. They were also referred by the Canadian Association of Friedreich's Ataxia and recruited from the entire province of Québec. In this clinic, multidisciplinary studies are conducted. ${ }^{13}$

We carried out a power calculation before starting the study, taking into account our previous open clinical trial. ${ }^{3}$ Initially, 28 patients with Friedreich's ataxia from a pool of 40 patients were included in the study. One female patient receiving active medication was taken out of the trial because of severe sleep disorders, hallucinations, and nightmares.

All patients with Friedreich's ataxia included in the trial fulfilled the diagnostic criteria of Harding. ${ }^{20}$ Of the 27 patients who completed the clinical trial, 23 had polyneuropathies and four were diabetic. All had a bilateral cerebellar and upper motor neuron syndrome, as shown by bilateral Babinski's signs. Twelve had dorsolumbar scoliosis. Sixteen were confined to wheelchairs and the remaining 11 had a severe ataxic gait. Dysmetria and coordination disorders of the upper limbs were: moderate-severe (eight patients), moderate (10 patients), or mild (nine patients). All were right handed. Brain CT showed cerebellar atrophy in 22 patients whereas the others were normal.

Initially, 36 patients with olivopontocerebellar atrophies from a pool of 46 patients were included in this study and received $\mathrm{AH}$ tablets. Six of them were dropped from the study. Three of these (two women, one man) receiving placebo were not compliant with the medication. A fourth man also receiving placebo, stopped the medication because of gastrointestinal side effects. Two patients with olivopontocerebellar atrophies (one woman, one man) on active medication dropped out because of a severe sleep disorder and loss of weight respectively. Whereas the sleep disorder occurred during the first three weeks and disappeared after stopping medication, the severe weight loss in the male patient (from $100 \mathrm{~kg}$ to $73 \mathrm{~kg}$ ) took place after one month of treatment.

The number of withdrawals from the subgroup of patients with olivopontocerebellar atrophies was relatively high (six out of 36) but we do not think that the exclusion of dropouts biased our results because: (1) patients dropped out before the minimum lapse of time (three months) needed for the second assessment; (2) our results concern only those patients who tolerated the medication.

Genetic studies were undertaken in Dr Guy Rouleau's laboratory. ${ }^{21}$ Among the 30 patients with olivopontocerebellar atrophies who completed this study there were two groups with autosomal dominant olivopontocerebellar atrophies 22 23 namely, six SCA-1 patients and 19 SCA-2 patients ${ }^{21}$ with slow saccadic eye movements belonging to the same family from 
Gaspé county. Additionally, we included three patients with recessive and two others with sporadic forms of olivopontocerebellar atrophy; in these patients, the diagnosis was made exclusively on clinical grounds. These four groups correspond to forms 3, 5, 1, and 2 of olivopontocerebellar atrophy from the clinical classification we used. ${ }^{24}$

Dysmetria and coordination disorders of the upper limbs were: moderate-severe (eight patients), moderate (nine patients), and mildmoderate (13 patients). Eight patients were confined to wheelchairs; the others had moderate (10 patients) and mild (12 patients) lower limb ataxias. Twelve had polyneuropathies. Four presented bilateral Babinski's signs. They did not have even mild parkinsonian signs, as evaluated by reinforcement methods. ${ }^{5}$

The condition of patients with Friedreich's ataxia and patients with olivopontocerebellar atrophies was stable, and they had no other medical or neurological disease. All patients with Friedreich's ataxia underwent clinical cardiological evaluation with ECGs, echocardiograms, and radioisotope ventriculography before entering the trial.

\section{STUDY DESIGN}

Both patient groups were admitted to hospital for four to five days in the metabolic ward of Hôtel-Dieu de Montréal Hospital before the trial.

Each group was randomly divided into two subgroups, one receiving two $\mathrm{AH}$ tablets of $100 \mathrm{mg}$ each, and the other, two placebo tablets of identical size, shape, and colour as the $\mathrm{AH}$ tablets. Patients were included randomly in order of presentation at the outpatient clinic. Randomisation was done by KG. The neurologists (MIB and OLP) as well as the neuropsychologist (TBM) were unaware at all times of the nature of treatment given to each patient. The protocol was approved by the research ethics board of Hôtel-Dieu de Montréal Hospital, and all patients gave their informed consent.

Treatment was given to each patient for three to four months. This lapse of time was necessary because of the availability of patients who came (many of them) from Gaspé county, about 500 miles from Montreal, and also because of climatic conditions-namely, the long Canadian winter. Due to such conditions, one patient with olivopontocerebellar atrophy from Gaspé county was examined after five months (table 1). At the end of the

Table 1 Clinical characteristics of patients

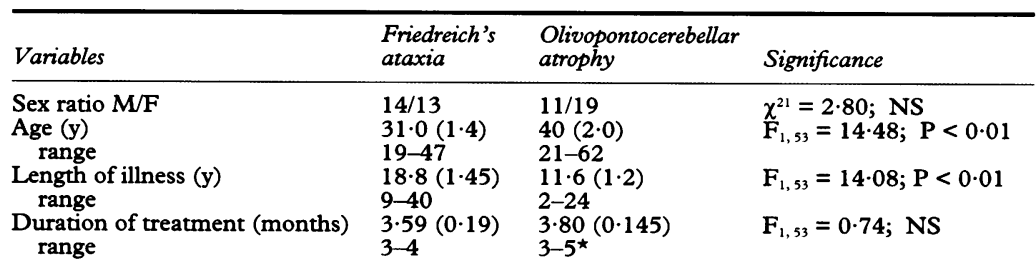

Except for sex ratio, all data are mean values (SEM). There was no significant difference in the characteristics of patients treated with $\mathrm{AH}$ and those who received placebo.

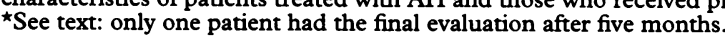

trial, the patients answered questionnaires about their subjective feelings and the side effects of treatment; assessments of RT and MT were performed on the same day and at the same hour as the baseline evaluation.

Both objective (RT, MT) and clinical neurological evaluations were recorded in the files before information about treatment was disclosed by the pharmacist (KG) at the end of the trial.

\section{STATISTICS}

Differences in RT and MT post-treatment values from baseline were assessed for significance within each subgroup by analysis of variance (ANOVA). The comparative effects of $\mathrm{AH}$ and placebo were evaluated by two way (two drug treatments by two diseases) analysis of covariance (ANCOVA) in which baseline values served as covariates for outcome values. A single common slope of regression was used whenever heterogeneity of regression was not seen at $10 \%$. In this case, the slopes for the two categories of patients or those of the two drug treatments were used in multiple regression analysis.

\section{Results}

Table 1 gives the clinical characteristics of the patients. The patients with Friedreich's ataxia were younger than patients with olivopontocerebellar atrophies but their illness was of significantly longer duration. There was no significant difference in the duration of treatment between patients with Friedreich's ataxia and those with olivopontocerebellar atrophies $\left(F_{1,53}=0.74\right.$, NS). The mean duration of placebo treatment was mean (SEM) 3.68 $(0 \cdot 138)$ months whereas the mean duration for active treatment was $3.72(0.187)$ months. The difference was not statistically significant $\left(F_{1,53}=0.01, N S\right)$.

No improvement was seen in both subgroups of patients with Friedreich's ataxia in terms of their lower limbs on both subjective assessment and neurological examination.

Subjective improvement on the self evaluation questionaire was reported by 22 patients, nine with Friedreich's ataxia and 13 with olivopontocerebellar atrophies. Except for four patients, all those who reported improvement had been treated with $\mathrm{AH}(\mathbf{P}<0.002)$.

At the end of treatment, neurological examination (blind assessment of ataxias in the upper limbs) indicated that 15 out of 29 patients were improved with $\mathrm{AH}$ and one of 28 was improved with placebo $(P<0.0001)$. Improvement with the active drug was found in patients with Friedreich's ataxia $(P<0.05)$ and patients with olivopontocerebellar atrophies $(P<0.001)$. In terms of magnitude of this effect, the ataxia scores at the level of the upper limbs were improved by $20 \%$ in patients with Friedreich's ataxia and $35 \%$ in patients with olivopontocerebellar atrophies.

In terms of side effects during treatment, which was not discontinued during the trial, two patients receiving $\mathrm{AH}$ had some loss of appetite during the third month. A third 
Table 2 Reaction time (RT) and movement time (MT) before and after treatment

\begin{tabular}{|c|c|c|c|c|c|c|c|c|}
\hline \multirow[b]{3}{*}{ Variables } & \multicolumn{4}{|c|}{ Friedreich's ataxia } & \multicolumn{4}{|c|}{ Olivopontocerebellar atrophy } \\
\hline & \multicolumn{2}{|c|}{$\begin{array}{l}\text { Placebo group } \\
n=13(6 M, 7 F)\end{array}$} & \multicolumn{2}{|c|}{$\begin{array}{l}\text { Amantadine group } \\
n=14(8 M, 6 F)\end{array}$} & \multicolumn{2}{|c|}{$\begin{array}{l}\text { Placebo group } \\
n=15(6 M, 9 F)\end{array}$} & \multicolumn{2}{|c|}{$\begin{array}{l}\text { Amantadine group } \\
n=15(5 \mathrm{M}, 10 \mathrm{~F})\end{array}$} \\
\hline & Before & After & Before & After & Before & After & Before & After \\
\hline $\begin{array}{l}\text { VRT-R } \\
\text { VRT-L } \\
\text { VMT-R } \\
\text { VMT-L } \\
\text { ART-R } \\
\text { ART-L } \\
\text { AMT-R } \\
\text { AMT-L }\end{array}$ & $\begin{array}{l}476 \cdot 0(49 \cdot 7) \\
508 \cdot 0(67 \cdot 4) \\
680.0(110 \cdot 1) \\
745 \cdot 0(136 \cdot 6) \\
378.0(29 \cdot 7) \\
405 \cdot 0(53 \cdot 4) \\
588 \cdot 0(90 \cdot 7) \\
809 \cdot 0(255 \cdot 7)\end{array}$ & $\begin{array}{l}460.0(50.0) \\
515.0(89.7) \\
681.0(111.4) \\
825.0(193.8) \\
365.0(31.7) \\
396.0(58.5) \\
590.0(85.7) \\
782.0(215.1)\end{array}$ & $\begin{array}{c}472 \cdot 0(51 \cdot 7) \\
539.0(66 \cdot 4) \\
632.0(92 \cdot 4) \\
999.0(175 \cdot 2) \\
412.0(47 \cdot 8) \\
480.0(73 \cdot 2) \\
696.0(115 \cdot 6) \\
1010.0(218 \cdot 8)\end{array}$ & $\begin{array}{l}448.0(45 \cdot 4) \\
489.0(52 \cdot 4)^{\star} \\
561 \cdot 0(103 \cdot 8) \\
651 \cdot 0(100 \cdot 8)^{\star} \\
356.0(30 \cdot 0)^{\star} \\
438.0(63 \cdot 5)^{\star \star} \\
556.0(82 \cdot 8) \\
576.0(76 \cdot 5)^{\star}\end{array}$ & $\begin{array}{l}416.0(26.5) \\
430.0(28.4) \\
517.0(62.5) \\
605.0(80.0) \\
314.0(23.6) \\
326.0(19.7) \\
483.0(86.9) \\
477.0(46.7)\end{array}$ & $\begin{array}{l}427 \cdot 0(27 \cdot 5) \\
471 \cdot 0(36 \cdot 7) \\
558 \cdot 0(77 \cdot 9) \\
641 \cdot 0(101 \cdot 0) \\
334 \cdot 0(24 \cdot 0) \\
350 \cdot 0(24 \cdot 6) \\
499 \cdot 0(65 \cdot 0) \\
588 \cdot 0(109 \cdot 6)\end{array}$ & $\begin{array}{l}453.0(37.2) \\
425.0(38.8) \\
520.0(59.3) \\
623.0(88.5) \\
357.0(34.3) \\
367.0(34.5) \\
479.0(53.6) \\
552.0(93.9)\end{array}$ & $\begin{array}{l}391.0(24 \cdot 7)^{\star} \\
347.0(24.1)^{\star} \\
458.0(56.0)^{\star} \\
482.0(66.7)^{\star \star} \\
311.0(20.4)^{\star} \\
316.0(19.8)^{\star} \\
386.0(31.9) \\
423.0(64.9)^{\star \star}\end{array}$ \\
\hline
\end{tabular}

Values are means (SEM) ms.

VRT-R, VRT-L = visual reaction time with the right and left hand; ART-R, ART-L = auditory reaction time with the right and left hand; VMT-R, VMT-L, AMT-R and AMT-L = visual movement time with the right and left hand and auditory movement time with the right and left hand.

$\star \mathrm{P}<0.05 ; \star \star \mathrm{P}<0.01$, final $v$ baseline values.

Table 3 Effect of amantadine treatment

\begin{tabular}{lclcl}
\hline & $\begin{array}{l}\text { Friedreich's } \\
\text { ataxia }\end{array}$ & Pvalue & $\begin{array}{l}\text { Olivopontocerebellar } \\
\text { atrophy }\end{array}$ & $P$ value \\
\hline VRT-R & $10(58 \cdot 4)$ & NS & $64(55 \cdot 1)$ & $<0.05$ \\
VRT-L & $31(61 \cdot 3)$ & NS & $80(57 \cdot 8)$ & $<0.05$ \\
VMT-R & $74(121 \cdot 4)$ & NS & $104(65 \cdot 5)$ & $<0.01$ \\
VMT-L & $264(157 \cdot 2)$ & $<0 \cdot 01$ & $236(148 \cdot 3)$ & $<0.01$ \\
ART-R & $23(40 \cdot 6)$ & NS & $63(38 \cdot 3)$ & $<0.01$ \\
ART-L & $20(44 \cdot 1)$ & NS & $84(41 \cdot 6)$ & $<0.01$ \\
AMT-R & $97(131 \cdot 9)$ & NS & $110(124 \cdot 4)$ & NS \\
AMT-L & $200(164)$ & $<0.05$ & $427(154 \cdot 7)$ & $<0.01$ \\
\hline
\end{tabular}

Values are adjusted difference ( $\pm 95 \% \mathrm{CI}$ ).

For abbreviations see table 2 . patient had insomnia and nightmares only during the first two weeks of AH treatment. A fourth patient receiving $\mathrm{AH}$ had insomnia, difficulties in concentration, and mood changes (some degree of depression) in the third month of the trial.

Whereas the clinical findings are mainly of informative value, the objective effect of $\mathrm{AH}$ treatment in this study was evaluated exclusively by RT and MT assessments.

Table 2 presents the RT and MT values of the four subgroups. Patients with Friedreich's ataxia and patients with olivopontocerebellar atrophies receiving $\mathrm{AH}$ improved in comparison with those receiving placebo.

When comparing the effects of $\mathrm{AH}$ with those of placebo, there were significant interactions with the disease for most variables studied. Therefore, differences between the two treatments were estimated separately for Friedreich's ataxia and olivopontocerebellar atrophies (table 3). Patients with olivopontocerebellar atrophies were significantly improved on seven RT and MT measures. Patients with Friedreich's ataxia were significantly improved on two MT measures only: visual MT with the left hand (VMT-L) and auditory MT with the left hand (AMT-L).

Among the 27 patients with Friedreich's ataxia, $19(70.3 \%)$ asked to continue with $\mathrm{AH}$ treatment whereas among the 30 patients with olivopontocerebellar atrophies, 27 (90\%) wanted to do so.

\section{Discussion}

We were unable to include more patients. Nevertheless, we are convinced that the improvement with AH treatment in this study is significant because the results are in agreement with those found in the previous open clinical trial. ${ }^{3}$ The beneficial actions of $\mathrm{AH}$, considered to be related to its enhancement of dopamine release or inhibition of dopamine reuptake, were reported with some neurobehavioural and neuropsychological performances. ${ }^{25-27}$ The percentage of side effects in our study was similar to that reported in other investigations. ${ }^{28}$ As already reported, ${ }^{28}{ }^{29}$ the major side effects in patients who discontinued treatment as well as the minor side effects in patients who completed the study promptly disappeared with the cessation of medication.

The following points must be made regarding the rationale of $\mathrm{AH}$ treatment in patients with olivopontocerebellar atrophies and patients with Friedreich's ataxia Firstly, during the past few years, dopaminergic innervation of the cerebellum in mammals has been fully documented. ${ }^{3031}$ As stated in a previous paper, $^{3}$ we initiated $\mathrm{AH}$ treatment in spinocerebellar degeneration because we found low CSF HVA concentrations in our patients with olivopontocerebellar atrophies or Friedreich's ataxia, in agreement with data from other laboratories. ${ }^{32}$ In some conditions, there is a relation between dopamine innervation of the striatum and degeneration of the olivocerebellar system. ${ }^{33}$ Experimental dopamine depletion impairs RT ${ }^{34-36}$ Go and no go tasks as well as visual RT in monkeys are dependent on noradrenaline/dopamine balance. ${ }^{37}$ Low dopamine and HVA concentrations have been recorded in the striatum of patients with end stage, dominantly inherited olivopontocerebellar atrophy. ${ }^{38}$ Parkinsonian features are not as common as generally supposed in patients with olivopontocerebellar atrophies. Two patients from our series with mild akinesia and rigidity were excluded from this study (see methods). Therefore, none of our 30 patients with olivopontocerebellar atrophies exhibited akinesia. The findings of Kish $e t$ $a^{38}$ are similar to ours: none of their 14 patients with olivopontocerebellar atrophy had akinesia or ridigity.

Both tables 2 and 3 show an unforeseen result-namely, the improvement with $\mathrm{AH}$ was more striking with use of the left hand, which tests right hemispheric performance. To explain these handedness differences: (1) we think that there are no methodological problems because patients started RT and MT performances randomly with the right or left 
hand; (2) there is right hemispheric superiority for sustained attention tasks, ${ }^{39}$ a function which is basically involved in both RT and MT performances; (3) the mesolimbic dopamine system is implicated in incentive motivational processes by which evaluative processes are translated into action; whereas this sustained attentional system is underlaid mainly by dopaminergic mesolimbic projections ${ }^{36}$ selective attentional and arousal mechanisms are underpinned by noradrenergic projections ${ }^{40}$; moreover, the mesolimbic system is also intimately involved in the control of motor behaviour and higher integrative functions $^{3641} ;(4)$ in both humans and animals, relatively higher concentrations of dopamine are found in the left hemisphere than in the right ${ }^{42}$ whereas the reverse is true for noradrenaline. ${ }^{43}$

Our hypothesis concerning this handedness difference is that the dopaminergic deficit could be partially responsible for the better improvement of RT and MT performances because sustained attention is mostly dependent on the mesocortical dopaminergic system. The lowering of dopamine concentration involves both hemispheres in our patients with Friedreich's ataxia and patients with olivopontocerebellar atrophy, but: (a) the dopamine pool is initially higher in the left hemisphere, thus corresponding to the right hand ${ }^{42} ;(b)$ the lowering of dopamine concentration in the right hemisphere, which is dominant for sustained attention, could explain why replacement therapy would improve primarily the function of the left hand.

Although the impact of $\mathrm{AH}$ on dopamine release $^{44}$ may explain some of its therapeutic actions, this was certainly not the only factor involved for two reasons: (1) levodopa treatment did not induce an improvement of olivopontocerebellar atrophies ${ }^{45}$; (2) there was no parallelism between low CSF concentrations and improvement of patients with olivopontocerebellar atrophies in a previous open study. ${ }^{3}$

Secondly, earlier work ${ }^{214}$ has emphasised the possible role of glutamate toxicity in olivopontocerebellar atrophies. Glutamate turnover is high in the granule cell layer; granule cells, the predominant target of mossy fibres, seem to possess NMDA and at least one nonNMDA glutamate receptor. They are, therefore, able to respond to presynaptic glutamate mediated mossy fibre transmission. ${ }^{46}$

Thirdly, the neuronal damage associated with neurodegenerative disorders may be related to excitation of NMDA receptors. ${ }^{47}$ It has been shown that the neurotoxicity of glutamate and closely related agonists is mediated by NMDA receptors in cultured cerebellar granule cells. ${ }^{48-50}$

Fourthly, memantine, an AH analogue, is a potent blocker of NMDA receptor channels. ${ }^{50-52}$ We think that the action of $\mathrm{AH}$ on NMDA receptor channels provides another main explanation for the improvement found in our cases. In lurcher mutant mice, an animal model of olivopontocerebellar atrophy, amantadine and the NMDA receptor antagonist, ketamine, improved motor coordination in the coat hanger test. ${ }^{53}$
In summary, In this double blind clinical trial, (1) AH treatment for three to four months significantly improved some RT and MT scores (the speed of information processing, attention and motivation as well as motor performance evaluated at the level of the upper limbs only). (2) This study confirms some previous open clinical trials, ${ }^{1-4}$ but it must be underscored that on the whole improvement was more moderate than previously reported. ${ }^{4}$ Filla $e t ~ a l^{54}$ found a negative effect in patients with Friedreich's ataxia receiving a single $100 \mathrm{mg}$ dose of $\mathrm{AH}$ with ataxia scores recorded 90 minutes later. Their study is not directly comparable with the above cited investigations because of its acute nature. AH must be generally considered as replacement treatment, and its clinical action most probably requires more than 90 minutes. (3) In this short term trial, clinical improvement of motor coordination was striking in many cases of olivopontocerebellar atrophy, whereas it was mild or absent in patients with Friedreich's ataxia although their condition remained stable or was mildly improved objectively. (4) Finally, treatment with $\mathrm{AH}$ is justified for trial based on experimental data and the results of this study. The main difficulty with such treatments in these disorders is that neurotransmitter deficiencies are probably multifactorial. ${ }^{32}$

This work was supported by grants from the Du Pont Merck Pharmaceutical Company, Wilmington, Delaware, USA and the Canadian Association of Friedreich's Ataxia. We are indebted to Mr Ovid Da Silva for his editorial input and to Mrs Michèle Mathieu for her secretarial work. AH and placebo pills were provided by the Du Pont Merck Pharmaceutical Company.

1 Botez T, Botez MI, Parent C, Courchesne Y. Etude préliminaire évaluant l'effet à court terme de l'amantadine et du L-tryptophane associé au carbidopa dans le traitement des ataxies spinocérébelleuses. Méd Sci 1988 2(suppl 1):46A

2 Botez MI, Young SN, Botez T, Courchesne Y. Treatment of Friedreich's ataxia with amantadine letter. Neurology 1989;39:749-50.

3 Botez MI, Young SN, Botez T, Pedraza OL. Treatment of heredo-degenerative ataxias with amantadine hydrochloride. Can F Neurol Sci 1991;18:307-11.

4 Petersen PL, Saad J, Nigro MA. The treatment of Friedreich's ataxia with amantadine hydrochloride. Friedreich's ataxia with
Neurology 1988;38:1478-80.

5 Noica D, Draganesco S. Sur un symptôme caractéristique d'une lésion des noyaux centraux moteurs: la rigidite musculaire latente. Rev Neurol 1935;63:75-9.

6 Botez MI, Léveillé J, Lambert R, Botez Th. Single photon emission computed tomography (SPECT) in cerebellar disease: cerebello-cerebral diaschisis. Eur Neurol 1991;31 405-21.

7 Smedley hand dynamometer. Manual. Chicago: Stoelting Company, 1972:2. (Catalog number 19117.)

8 Benton AL, Blackburn HL. Practice effects in reaction time tasks in brain-injured patients. fournal of Abnormal Social Psychology 1957;54:109-13.

9 Ladurner G, Tschinkel M, Klebb H. Reaction time in cerebrovascular disease. Arch Gerontol Geriat 1985;4:373-9.

10 Baker SJ, Maurissen JP, Chrzan GJ. Simple reaction time and movement time in human volunteers. Percept Mot Skills 1986;63:767-74.

11 Botez MI, Gravel J, Attig E, Vézina JL. Reversible chronic cerebellar ataxia after phenytoin intoxication: possible role of the cerebellum in cognitive thought. Neurology 1985;35:1152-7.

12 Botez MI, Botez-Marquard T, Elie R, Attig E. Role of the cerebellum in complex human behavior. Ital $\mathcal{f}$ Neurol Sci 1989;10:291-300

13 Botez MI. Cerebellum. In: Ramachandran VS, ed. Encyclopedia of human behavior. San Diego: Academic Press 1994;1:549-60.

14 Birren JE, Woods AM, Williams MV. Behavioral slowing with age: causes, organization, and consequences. In Poon LW, ed. Aging in the 1980s: psychological issues. Washington, DC: American Psychological Association 1980:293-308.

15 Vernon PA. Speed of information processing and general intelligence. Intelligence 1983;7:53-70. 
16 Jensen AR. Spearman's g: links between psychometrics and biology. Ann NY Acad Sci 1993;702:103-29.

17 Spirduso WW, MacRae HH, MacRae PG, Prewitt J, Osborne L. Exercise effects on age motor function. Ann NY Acad Sci 1988;515:363-75.

18 Hamsher KS, Benton AL. The reliability of reaction time determinations. Cortex 1977;3:306-10.

19 Botez MI, Attig E, Vézina JL. Cerebellar atrophy in epileptic patients. Can $\mathcal{F}$ Neurol Sci 1988;15:299-303.

20 Harding AE. The inherited ataxias. In: Di Donato S, ed. Advances in neurology. New York: Raven Press, 1988;48: 37-45.

21 Lopes-Cendes I, Andermann E, Attig E, et al. Confirmation of the SCA-2 locus as an alternative locus for dominantly inherited spinocerebellar ataxias and refinement of the candidate region. Am 7 Hum Genet 1994;54:774-81.

22 Shut JW, Haymaker W. Hereditary ataxia; pathological study of five cases of common ancestry. $\mathcal{F}$ Neuropathol Clin Neurol 1951;1:183-213.

23 Wadia NH, Swammi RK. A new form of heredofamilial spinocerebellar degeneration with slow eye movements. Brain 1971;94:359-74.

24 Huang YP, Plaitakis A. Morphological changes of olivopontocerebellar atrophy in computed tomography and comments on its pathogenesis. In: Duvoisin RC, Plaitakis A, eds. Advances in neurology. New York: Raven Press, 1984;41:39-86.

25 Gualtieri T, Chandler $M$, Coons TB, Brown LT. Amantadine: a new clinical profile for traumatic brain injury. Clin Pharmacol 1989;12:258-70.

26 Ambrozi L, Danielczyk W. Treatment of impaired cerebral function in psychogeriatric patients with memantine. Pharmacopsychiatry 1988;21:144-6.

27 Horiguchi J, Imami Y, Shoda T. Effects of long-term amantadine treatment on clinical symptoms and EEG of a patient in

28 Flaherty JA, Bellur SN. Mental side-effects of amantadine therapy: its spectrum and characteristics in a normal population. $\mathcal{F}$ Clin Psychiat 1981;42:9.

29 Monto SA, Gunn RA, Bandyk MG, King CL. Prevention of Russian influenza by amantadine. $\mathscr{J} A M A$ 1979;241: 1003-6.

30 Panagopoulos NT, Papadopoulos GC, Matsokis NA. Dopaminergic innervation and binding in the rat cerebelDopaminergic innervation and bind

31 Efthimiopoulos S, Giompres P, Valcana T. Kinetics of dopamine and noradrenaline transports in synaptosomes from cerebellum, striatum and frontal cortex of normal from cerebellum, striatum and frontal cortex

32 Polinsky RJ, Brown RT, Burns RS, Harvey-White J, Kopin IJ. Low lumbar CSF levels of homovanillic acid and 5hydroxyindoleacetic acid in multiple system atrophy with hydroxyindoleacetic acid in multiple system atrophy with
autonomic failure. $\mathcal{f}$ Neurol Neurosurg Psychiatry 1988; 51:914-9.

33 Deutch AY, Elsworth JD, Roth RH, Goldstein M. 3Acetylpyridine results in degeneration of the extrapyramidal and cerebellar motor systems: loss of dorsolateral striatal dopamine innervation. Brain Res 1990;527: 96-102.

34 Amalric M, Kool DF. Depletion of dopamine in the caudate nucleus but not in the nucleus accumbens impairs reaction-time performance in rats. $\mathcal{f}$ Neurosci 1987;7: 2129-34.

35 Taghzouti K, Le Noal M, Simon H. Suppression of nora- drenergic innervation compensates for behavioral deficits induced by lesion of dopaminergic terminals in the lateral septum. Brain Res 1991;552:124-8.

36 Robbins TW, Everett BJ. Arousal systems and attention. In: Gazzaniga MS, ed. The cognitive neurosciences. Cambridge, Massachussetts: MIT Press, 1995:703-19.

37 Sawaguchi T. Catecholamine sensitivities of neurons related to a visual reaction time task in the monkey prefrontal cortex. $\mathcal{F}$ Neurophysiol 1987;58:1100-22.

38 Kish SJ, Robitaille Y, El-Awar M, Clark B, Schut L, Ball $\mathrm{JM}$, et al. Striatal monoamine neurotransmitters and metabolites in dominantly inherited olivopontocerebellar atrophy. Neurology 1992;42:1573-7.

39 Heilman KM. Attentional asymmetries. In: Davidson $\mathrm{RJ}$, Hugdahl $\mathrm{K}$, eds. Brain asymmetry. Cambridge, Massachussetts: MrT Press, 1994;9:217-23.

40 Tucker DM, Williamson PA. Asymmetric neural control in human self-regulation. Psychol Rev 1984;91:185-215.

41 Wittling $W$. Brain asymmetry in the control of autonomic-physiologic activity. In: Davidson RJ, Hugdahl $\mathrm{K}$ eds. Brain asymmetry. Cambridge, Massachussetts: KiT Press, 1994;12:305-10.

42 Louillot A, Le Moal M. Lateralized interdependence between limbicocortical and ventrostriatal dopaminergic transmission. Neuroscience 1994;59:495-500.

43 Oke A, Lewis R, Adams RN. Hemispheric asymmetry of norepinephrine distribution in rat thalamus. Brain Res 1980;188:269-72.

44 Von Voigtlander P, Moore K. Dopamine: release from the brain in vivo by amantadine. Science 1970;174:408-10.

45 Goetz CG, Tanner CM, Klawans HL. The pharmacology of olivopontocerebellar atrophy. Adv Neurol 1984;41: $143-8$

46 Oertel WH. Neurotransmitters in the cerebellum. Scientific aspects and clinical relevance. In: Harding AE, Deufel $T$ aspects and clinical relevance. In: Harding AE, Deufel T, 61:33-75.

47 Cox JA, Lysko PG, Henneberry RC. Excitatory amino acid neurotoxicity at the $\mathrm{N}$-methyl-D-aspartate receptor in cultured neurons: role of the voltage dependent magnesium block. Brain Res 1989;499:266-72.

48 Henneberry RC, Novelli A, Cox JA, Lysko PG. Neurotoxicity at the N-methyl-D-aspartate receptor in energy-compromised neurons. Ann NY Acad Sci 1989; 558:225-33

49 Boje KM, Wong G, Skolnik P. Desensitization of the NMDA receptor complex by glycinergic ligands in cerebellar granule cell culture. Brain Res 1993;603:207-14

50 Bormann J. Memantine is a potent blocker of N-methyl-Daspartate (NMDA) receptor channels. Eur $\mathcal{f}$ Pharmacol 1989;166:591-2.

51 Kornhuber J, Bormann J, Retz E, Hubers M, Riederer P. Memantine displaces $\left({ }^{3} \mathrm{H}\right) \mathrm{MK}-801$ at therapeutic conMemantine displaces (H) MK-801 at therapeutic concentrations in postmortem hum

52 Erdo SL, Schaefer M. Memantine is highly potent in protecting cortical cultures against excitotoxic death evoked by glutamate and $\mathrm{N}$-methyl-D-aspartate. Eur $\mathcal{f}$ Pharmacol 1991;198:215-7

53 Lalonde R, Joyal CC, Guastavino J-M, Côté C, Botez MI. Amantadine and ketamine-induced improvement of motor coordination in lurcher mutant mice. Restor Neurol Neurosci 1993;5:367-70.

54 Filla A, De Michele G, Orefice G, Campanella G. A doubleblind cross-over trial of amantadine hydrochloride in Friedreich's ataxia. Can $\mathcal{f}$ Neurol Sci 1993;20:52-5. 